\title{
Trust Basis of the School Principles According to the Teachers Working in Public Primary Schools
}

\author{
Sinan Özat \\ Kocaeli Provincial Directorate of Education \\ Email: sinanozat@hotmail.com \\ Soner Polat \\ Educational Sciences Department, University of Kocaeli, Izmit, Turkey \\ Email: spolat@kocaeli.edu.tr
}

\section{Doi:10.5901/jesr.2015.v5n2p233}

\section{Abstract}

The purpose of this research is to determine the trust basis of public primary school teachers towards the school managers in the Ministry of National Education,. In the model Qualitative research, the open-ended survey question "If you were a school principal what would you do to have the confidence?" was used to collect as a data collection tool. The data was collected by the participation of 197 teachers from 15 public primary school in Kocaeli. In the analysis of the data, beyond the types of content analysis, categorise analysis was used. As a result of research, 37 variables have been identified including, equality and fairness, impressive communication, participation in the profits, clarity, security, being relevant, cohesiveness, honesty, consistency, helpfulness, rewarding, empathy, being a model, organising social activity, expertise, integration, support, flexibility, motivation, value, making the physical environment, being respectful and tolerant, problem-solving, friendly, power distance, listening, tend to trust, kindness, confidentiality constructiveness, compliance with obligations remote control, aimoriented work, being disciplined, mediation, the accuracy and being criticism.

Keywords: Trust Basis, Trust Formers, School Principle, Teacher, Public Primary School.

\section{Introduction}

The trust concept is very wide-dimensional that it is regarded as an important factor for creating and maintaining relations between people by many sociologists, economists, psychologists, (Uzbilek, 2006). Trust is an important concept in all the basis of human relations that keeps people together from the psychological point and makes them feel secure (Unsal, 2004). At the same time, trust is situated between the social and organizational life of ethical values (Ozmen ve Gungor, 2008). The creation of the confidence for the organization is also extremely important for the realization the objectives of the organization (Yilmaz, 2004).

When the literature is analyzed, Five levels of trust tendency can be seen clearly; Self-esteem, interpersonal trust, organizational trust, system trust and public trust, depending on the side of reliance legibility. The trust of teachers to the school principals in the interpersonal trust level is handled as a vertical trust (Polat, 2009).

According to the data from the World Values Survey, Turkey is the lowest among the countries in the world in the level of confidence. The level of people saying in research done in 1990 "I rely on most of the people" \% 10 rate declined to \% 6,5 in 1997 (Oren, 2007).

Confidence in particular, job satisfaction, organizational justice, organizational identification, seize the initiativetaking behavior, employee morale, organizational commitment, group cohesion, organizational citizenship behavior, private investment in the relationship, problem solving skills, risk-taking, social responsibility, creativity, open organizational culture, knowledge creation and management, environmental compliance, decreased resistance to change, communication, cooperation, transfer of business decision-making process, control, organizational commitment, organizational climate, organizational efficiency, organizational settlement and teaching, organizational performance, department performance, individual performance, to facilitate the transfer of authority, is a positive relationship with the perception of the transfer of funds within the trust. However, stress, conflict, employee absenteeism, intention to leave is in a negative relationship with the perception of trust in organizational (Paker, 2009). As it has seen, trust is an important 
variable affected by organizational variables.

In the light of previous studies in case of insecurity, there is a considerably withdrawal and social isolation of the people's approaches (Polat, 2007). It is thought that If the teachers' trust levels increase they will work willingly and productively. This will improve the efficiency and effectiveness of the school. In this context, this study is important for organizations to explain the concept of trust, confidence in the foundations of elementary school principals to identify and uncover the important variables in order to increase confidence.

The purpose of this research is to determine the trust basis of the school managers by the public primary school teachers' dependent of Ministry of Education and to identify their variable basis according to gender, age and their branch.

\section{Research Method}

\subsection{Research Design}

The research was done to interpret and make sense of the events that are suitable for the existing conditions in the qualitative research approach. Qualitative research approach is based on an understanding of the theory and structure to create a research and understanding of social phenomena in their respective environment, an approach to the fore. This study is carried out by one of the patterns of qualitative research "science case" within the scope of the pattern. Case science studies often aimed individual perceptions or reveal a certain perspectives and interpretation of the phenomenon (Yildirim and Simsek, 2005).

\subsection{The Working Group}

The study group was carried out with on a voluntary basis with 197 teachers from 566 teachers from 15 public primary schools of the Ministry of National Education District in KOCAELI in the academic year 2011-2012. 197 teachers participated in the study, 95 participants are classroom teachers, 102 participants are branch teachers. Teachers who surveyed are 82 men and 115 women.

\subsection{Data Tool and Data Collection}

Within this research, the public primary school teachers in KOCAELI, for the purposes of the research, questionnaire was used to collect information. This technique was chosen because it enables the possibility of collecting large amounts of data easily as soon as possible from a broad group (Orucu, 2006). Survey conducted by the researchers consists of two parts. The first part is consisted of teacher's gender, age, seniority and personal information about their branches. In the second part, teachers wrote their views of an open-ended question which is: "If you were a school principal, what would you do for teachers to trust you?" dates of the research were collected between March 12 -13 April 2012 with the permission of the school administrations. Questionnaires distributed and collected from volunteer teachers.

\subsection{Data Analysis}

Teachers' answers to the research question were coded according to the research objectives. Then frequencies of responses were found. Thus, the qualitative data was quantification and it increased the reliability, and reduced bias comparisons could be made between the categories. In the research, Content analysis (categorical analysis) as used. Code and categories in the related concepts that have been effective in the article, as well as the resulting findings. In this study $T$ stands for the teacher when direct quotations used in . Every teacher is coded with a number. In addition to that $\mathrm{M}$ stands for the male teachers for, $\mathrm{F}$ stands for the woman teachers. Then it was written that the teacher's age, $\mathrm{B}$ stands for the branch teachers, $C$ stands for classroom teachers and years of seniority. (Example: T, 200, M, 50, C, 25). One of the researcher and the other for the reliability of the research conducted by two researchers, including nonexperts on the reliability of coding $=$ Visibility Union / Visibility Union + Vision formula applied to the separation $X$ 100 (Miles and Huberman, 1994). Agreement between the two researchers was calculated as $87 \%$. 


\section{The Results and Discussion}

As it is seen in Table 1 teacher's answers to the question "If you were a school principal what would you do to have the confidence" were collected in 37 titles. Rely on teachers as the basis for school principals generally fall into two categories were collected as personal and organizational variables. This variable was discovered 10 pieces do not fall into two categories; they are excluded from the scope of the research. In general, it can be said that they mentioned both the personal characteristics of school principals and their roles effected by the organizational variables within the school. Some of the answers given are not included in both two groups. Teachers see that the principal of trust as personal variables that make up the most "effective communication $(f=44)$, openness $(f=40)$, security $(f=40)$, being related to ( $f$ $=36)$, honesty $(f=30)$," while; roles of school principals from the organizational variables is the most "equality and fairness $(f=142)$, the decision added $(f=49)$, open climate $(f=33)$, reward $(f=27)$, to organize social events $(f=23)$ ".

Table 1. School Managers Confidence Creator Personal and Organizational Variables

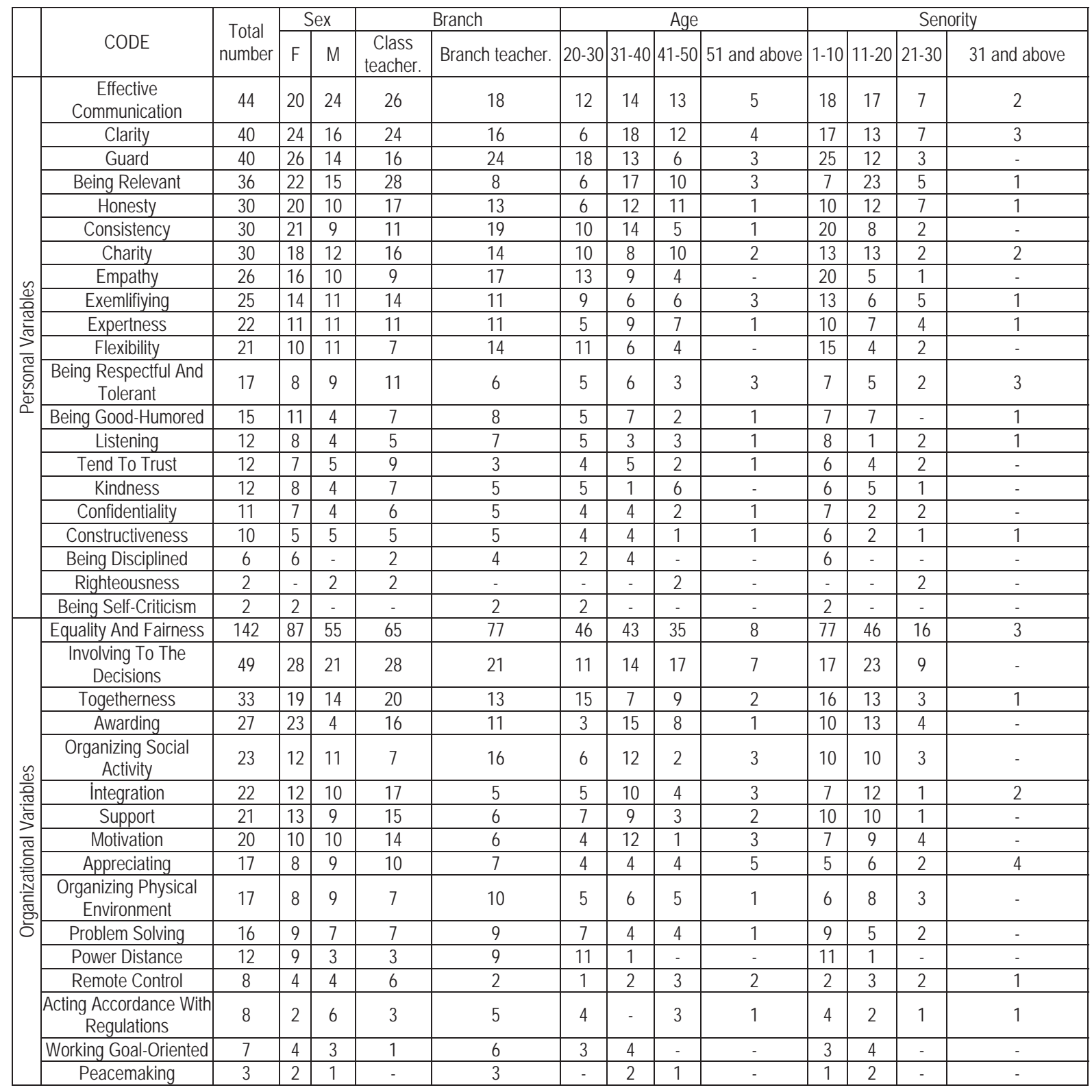




\subsection{Personal Variables}

\subsubsection{Effective Communication}

44 teachers emphasized for "effective communication" the basis of trust for the principal. Classroom teachers $(f=26)$ and between 0-10 years of professional seniority of teachers $(f=18)$, referred to the more effective communication (Table 1). Communication influences the level of confidence between employees and managers. Managers communicate effectively with staff available during exchange of ideas and feelings environment, is one of the factors enhancing confidence in the manager. To the correct explanations for decisions, to ensure timely and accurate feedback to increase trust between managers and employees (Demircan and Ceylan, 2003; Asunakutlu, 2002).

\subsubsection{Clarity}

40 teachers emphasized "clarity" as the basis of trust the principal. More teachers who are 31-40 age range ( $f=18$ ) seniority years between 0-10 years and professional teachers $(f=17)$, emphasized clarity (Table 1$)$. Contemporary management must be transparent. Friendly behaviors are the deter minders of a peaceful environment (Gumus, 1999). Privacy makes doubts and knowing that who the people and what they are doing reinforces the social relations and improves the trust. Openness and trust is closely linked to each other. Unless there is clarity, it is difficult to maintain confidence. It requires a range of stakeholders to share information with their employees. Openness increases the reliability of the opposing party (Erdem, 2003).

\subsubsection{Guard}

40 teachers emphasized the "guard" as a basis for the principal of trust. Schoolmistresses $(f=26)$, who is the age range 21-30, teachers $(f=18$ ) aged between 0-10 professional length of service and professional teachers $(f=25)$, notedprotection is more variable (Table 1). Guard is defined as protecting someone or something from external dangers, keep away from a difficult situation, sparing and preserving (TDK, 2012).

\subsubsection{Being relevant}

36 teachers emphasized "being relevant" as the basis of trust the principal. Classroom teachers $(f=28)$, which is the age range 31-40 teachers ( $f=17$ ) aged between 11-20 profession length of service and professional teachers $(f=23)$ emphasized the importance of being relevant (Table 1). There are some behaviors for developing the trust. These are; being sensitive to teachers' needs, protecting their interests, abstaining from exploiting ones' while protecting others'. Managerial behaviors of the employees to provide the peace in their groups make the managers trustworthy and benevolent (Egerci, 2009).

\subsubsection{Honesty}

30 teachers emphasized "honesty" as the basis of trust the principal. It is seemed that schoolmistresses $(\mathrm{f}=20)$, and the teachers whose age range is between 31-40 ( $f=12)$ ve $41-50(f=11)$ and professional length of service 0-10 years $(f=10)$ and $11-20$ years $(f=12)$ emphasized the importance of honesty more than the others (Table 1$)$. The observations of the employees about the coherences of theirs managers' expressions and actions are affected by their detections of their honesty, accuracy and moral values. (Egerci, 2009; Polat, 2007; Cubukcu, 2010; Boru, 2001; Erdem, Aytemur and Karaman, 2007, Eser, 2007; Erdem et all, 2006; Paker, 2009). As long as the managers are trustworthy, they gain the confidence the employees (Gumus, 1999).

\subsubsection{Consistency}

30 of the teachers emphasized "consistency" as the basis of trust the principal. Mostly schoolmistresses $(f=21)$, and the teachers whose age range is between $31-40(f=14)$ and whose professional length of service is between $0-10$ year $(\mathrm{f}=20)$, emphasized the consistency as a trust basis (Table 1$)$. Mangers consistent behaviors satisfy the predictability of their behaviors. This satisfies the employees to take risks in their relationship between their managers. Predictable positive behaviors raise the level of trust (Egerci, 2009; Cubukcu, 2010; Eser, 2007; Boru, 2001; Erdem et all, 2006; 
Paker, 2009).

\subsubsection{Charity}

30 of the teachers emphasized "charity" as the basis of trust the principal. The teachers whose professional length of services are between 0-10 years ( $f=13)$ ve $11-20$ years $(f=13)$, emphasized the charity more that the others (Table 1$)$. Charity is the desire of the manager's to do good things to their subordinates without taking their interest into the consideration (Mayer ve other., 1995). A charitable manager behaves friendly and helps his/her subordinates. And this makes him to be perceived as a charitable and trustworthy (Tan and Tan, 2000).

\subsubsection{Empathy}

26 of the teachers emphasized "empathy" as the basis of trust the principal. Branch teachers $(f=17)$, teacher whose age rank is 21-30 ( $f=13)$ and the teachers whose professional length of service is between 1-10 years $(f=20)$ emphasized the empathy more than the others (Table 1). Empathy is to put him/herself in the others' place and considering the situation from their point of view and to understand them correctly. In other words, empathy can be thought as to be able think, feel like others and to respond as well (Pala, 2008).

\subsubsection{Exemplifying}

25 teachers emphasized "exemplifying" as the basis of trust the principal. The teachers whose professional length of service is between $0-10$ years $(f=13)$, emphasized exemplifying more then the others (Table 1$)$. Exemplifying is defined as a value of the state and the nature of being adopted. (Erdemler Dictionary, 2007).

\subsubsection{Expertness}

22 of the teachers emphasized "expertness" as the basis of trust the principal. Most of the teachers whose professional length of service is between $0-10$ years $(f=10)$ emphasized the expertness more than the others (Table 1$)$. Expertness is to work by having the enough outfit and the skills without harming the others (Robbins and Decenzo, 2000).

\subsubsection{Flexibility}

21 teachers emphasized "flexibility" as the basis of trust the principal. Branch teachers $(f=14)$ whose age rank is between 21-30 ( $f=11)$ and whose professional length of service is between 0-10 years $(f=15)$, emphasized flexibility much more than others (Table 1). There are many ways to be successful. If it is insistent on one way and make the bureaucratic structure is to done with scrupulous care people can be hurt. To be successful in management people sometimes must behave flexible.(Gumus, 1999).

\subsubsection{Being Respectful and Tolerant}

17 of the teachers emphasized "being respectful and tolerant" as the basis of trust the principal. Classroom teachers $(\mathrm{f}=11)$ emphasized the importance of being respectful and tolerant as the basis of trust (Table 1 ). Respect is behaving carefully, regard fully towards a person because of being superior, older, and useful and holly which cause feeling of love (TDK, 2012). Tolerance is appreciating everything as much as possible, indulgence and showing tolerance (TDK, 2012).

\subsubsection{Being Cheerful}

15 teachers emphasized "being cheerful" as the basis of trust the principal. School mistresses $(f=11)$ emphasized the importance of being cheerful more than others (Table 1). Being cheerful is defined as a way of behavior done by sincerely and natural and it is seen as a reflection of good mood (Erdemler Dictionary, 2007). 


\subsubsection{Listening}

12 teachers emphasized "listening" as the basis of trust the principal. The teachers whose professional length of service is between 0-10 years $(\mathrm{f}=8)$ emphasized the importance of listening more than others (Table 1$)$. In Turkish Language Society Dictionary, (TDK, 2012), listening is defined as the job of listening, but in Erdemler Dictionary (2007) it is defined not only to hear but also to evaluate the expressions actively. In the process of communication the people who feel to be listened trust the person who listens to them.

\subsubsection{Tend to Trust}

12 teachers emphasized "tend to trust" as the basis of trust the principal. It is seem that branch teachers $(f=9)$, mentioned about tend to trust more than others (Table 1). Surveillance based on the extreme insecurity trend creates insecurity. Trusting and respectful trend doesn't shatter the trust but improves (Erdem, 2003).

\subsubsection{Kindness}

12 teachers emphasized "kindness" as the basis of trust the principal. School mistresses $(f=8)$ give impotence to kindness (Table 1). Kindness is defined as to behave in a polite, kind way. (TDK, 2012) and it enables as to discriminate the bad and good behaviors (Wikipedia, 2012).

\subsubsection{Confidentiality}

11 teachers emphasized "kindness" as the basis of trust the principal. The teachers whose professional length of service is between 0-10 years emphasized confidentiality more than others (Table 1). Confidant is defined as a person who knows the secret of someone and very close to him/her and confidentiality defined as being confidant (TDK, 2012).

\subsubsection{Constructiveness}

12 teachers emphasized "contractiveness" as the basis of trust the principal. Mostly, the teachers whose professional length of service is between 0-10 years ( $f=6)$, talked about the importance of constructiveness (Table 1). Constructiveness is defined as avoiding dividing, dismembering but being helpful and collateral. (Erdemler Dicitionary, 2007) If the managers behave in a helpful way, the people around them will trust them.

\subsubsection{Being Disciplined}

6 teachers emphasized "being disciplined" as the basis of trust the principal. The teachers who emphasized being disciplined are school mistresses and whose professional length of service is between $0-10$ years $(\mathfrak{f}=6)$ (Table 1$)$. Being disciplined is the ability of understanding a situation, to decide how to behave for that situation and apply the ability without parental care. (Mahiroglu, Buluc, 2003).

\subsubsection{Righteousness}

2 teachers emphasized "righteousness" as the basis of trust the principal (Table 1). Match the reality of thought, judgment and propositions is defined as the fair (Erdemler Dictionary, 2007). People who are perceived to be reliable based on the accuracy of their behavior by the others.

\subsubsection{Self-criticism}

2 teachers emphasized "righteousness" as the basis of trust the principal (Table 1). Self-criticism refers to the pointing out of things critical/important to one's own beliefs, thoughts, actions, behavior or results; it can form part of private, personal reflection or a group discussion (Wikipedia, 2010). 


\subsection{Organizational Variables}

\subsubsection{Equality and Fairness}

142 teachers emphasized "equality and fairness" as the basis of trust the principal. School mistresses $(f=87)$ and the teachers whose length of service is between 0-10 years $(\mathrm{f}=77)$, emphasized equality and fairness more than others (Table 1). Equality is defined as two or more things are equal but fairness is defined as someone who works in the justice, justice (TDK, 2012).

\subsubsection{Involving to the Decisions}

49 teachers emphasized "involving to the decisions" as the basis of trust the principal. Teachers who emphasized "equality and fairness" as the basis of trust the principal are have 11-20 years length of service $(\mathrm{f}=23)$ (Table 1$)$. Involving the employees to the decision process is one of the important elements. The level of the allowance for the decision process will help gaining the confidence. Form the point of social exchange theory, sharing and recirculating is regarded as social awards. Because these awards symbolize the reciprocal social benefits, it will improve the trust towards the managers (Egerci, 2009; Polat, 2007; Yılmaz, 2006; Asunakutlu, 2002; Sisman, 2002).

\subsubsection{Togetherness}

33 teachers emphasized "togetherness" as the basis of trust the principle. It is seem that the teachers who are between 21-30 years old ( $f=15$ ) emphasized togetherness more than others (Table 1$)$. Togetherness conveys the organizational situation which the people in the organization are strongly together. There is a candid relation among the people who works together. The employees are satisfied by it. The teachers emphasized that they trust to the school principles who tries to make a friendly environment at school more than the others (Dincer, 1996).

\subsubsection{Awarding}

27 teachers emphasized "togetherness" as the basis of trust the principle. School mistresses ( $\mathrm{f}=23$ ), the teachers between 31-40 years old ( $f=15)$ emphasized the importance of rewarding (Table 1$)$. It is said that real benefits help to improve the trust (Erdem, 2003).

\subsubsection{Organising Social Events}

23 teachers emphasized "organizing social events" as the basis of trust the principle. Branch teachers $(f=26)$ and the teachers who are between 31-40 years old ( $f=12$ ) emphasized organizing social events more than others (Table 1 ). Organizing social events can be defined as to gather the employees in order make them social. School principle who responds to the teachers' interest and organizes social events gain the confidence from the teachers more than others.

\subsubsection{Integration}

23 teachers emphasized "organizing social events" as the basis of trust the principle. Branch teachers ( $f=17)$, the teachers who are between 31-40 years old $(f=10)$ and whose professional length of service is between 11-20 years $(f=12)$, said that integration is important (Table 1). Integration is to make effort to buck the all units of the organization up to work together and coordinated (Dinçer, 1996). A compatible group is a must for an efficient coordination. The managers who make a compatible group are more successful (Gumus, 1999).

\subsubsection{Support}

23 teachers emphasized "organizing social events" as the basis of trust the principle. Classroom teachers ( $f=12$ ) emphasized the support more than others (Table 1). In Turkish Language Society, (TDK, 2012), it is defines as to be helpful materially and morally, abutment. Encouraging the employees and supporting them improve the success of the manager (Gumus, 1999). 


\subsubsection{Motivation}

20 teachers emphasized "organizing social events" as the basis of trust the principle. Classroom teachers ( $\mathrm{f}=14$ ), the teachers who are between31-40 ( $\mathrm{f}=12$ ) emphasized the importance of motivation (Table 1). Motivation is the sum up of the efforts for the people who are motivated to achieve their goals (Eren, 1998). Encouraging and prompting the employees make them feel that they are important (Gumus, 1999).

\subsubsection{Appreciating}

17 teachers emphasized "appreciating" as the basis of trust the principle (Table 1). Appreciating people and their thoughts can be used as a valuing. When teacher feel they are appreciated trust their managers more.

\subsubsection{Organizing the Physical Environment}

17 teachers emphasized "organizing the physical environment" as the basis of trust the principle (Table 1). Works in the organization can be defined as retrofitting and organizing the relaxing and social areas and organizing the environment that the teachers need. The managers who make an effort to retrofit the physical environment is gain the confidence of the teachers.

\subsubsection{Problem Solving}

16 teachers emphasized "problem solving" as the basis of trust the principle. It is seemed that teachers whose professional length of service is between 0-10 years $(\mathrm{f}=9)$ emphasized problem solving more than others (Table 1 ). Manager is the person who solves the problems. The main property of a successful manager is to popularize the complexity which creates pressure. Problem solving requires responsibility. Managers mustn't only listen to the complaints of the employees; they must create a solution (Gumus, 1999).

\subsubsection{Power Distance}

12 teachers emphasized "power distance" as the basis of trust the principle. School mistresses $(f=9)$, branch teachers $(f=9)$, the teachers who are between 21-30 years old $(f=11)$ and whose professional length of service is between 1-10 years $(\mathrm{f}=11)$ mentioned about the importance of power distance (Table 1). Power distance means the feeling level of the power distance between the manager and the ruled. In other words, degrees of members of the community to accept the unequal distribution of power (Hofstede, 1989; Hofstede, 1994, Terzi, 2000).

\subsubsection{Remote Control}

8 teachers emphasized "problem solving" as the basis of trust the principle. Classroom teachers $(\mathrm{f}=6)$, pointed out the remote control more than others (Table 1). Control can be defined as the results of the operations of the organizations compared to the objectives, policies, plans and strategies to be kept within acceptable limits. Auditing should not be made a permanent tool of oppression. This can disrupt the health and morale of the team as well as managers (Gumus, 1999).

\subsubsection{Acting in Accordance with Regulations}

8 teachers emphasized "acting in accordance with regulations problem solving" as the basis of trust the principle. Mostly, schoolmasters $(\mathrm{f}=6)$, believes the importance of acting in accordance with regulations (Table 1$)$. Acting accordance with regulations can be defined as that the manager knows the laws and regulations and behaves according to them. The schools principles who behave according to the regulations avoid arbitrary acts and behave fair and equal seem to be more trustworthy. 


\subsubsection{Working Goal-Orientated}

8 teachers emphasized "working goal-orientated" as the basis of trust the principle. Branch teachers $(\mathfrak{f}=6)$ emphasized working goal-orientated more than others (Table 1). Goal-oriented work can be defined as to act in accordance with the short-and long-term goals at the organization. If the managers work goal-orientated and make the teachers feel that, they can be trusted easier.

\subsubsection{Peacemaking}

3 teachers emphasized "peacemaking" as the basis of trust the principle. All of them are branch teachers $(\mathrm{f}=3)($ Table 1$)$. Peacemaking is the most efficient method to overcome the problem of the people in conflict with the help of a bystander (Wikipedia, 2012).

\section{Summary and Concluding Remarks}

As the result of the research 37 variables have been defined as basis of trust principle like "equality and fairness, involving to the decisions, effective communication, clarity, guard, being relevant, togetherness, honesty ,consistency , helpfulness, awarding, empathy, modeling, organizing social events, expertness, integration, hand-holding, flexibility, motivating, appreciating, organizing physical environment, being respectful and tolerant, problem solving , being goodhumored, power distance, listening, tend to trust, kindness, confidentiality, constructiveness, acting accordance with the regulations, remote control, working goal-orientated, being disciplined, peacemaking, righteousness, being self-critism. Constituting the basis of 37 variables for teachers to trust the school principals as a general "personal variables" and "organizational variables" were collected in two categories. In this context, a model is created which can develop the trust towards the managers by the teachers at schools (Figure 1).

As the schools are human-human organizations, there is a high level of information exchanges at schools. In order to have a comfortable communication at schools, there should be a trustworthy environment at schools. The development of relations based on mutual trust between school principals and teachers in school affects the efficiency and effectiveness of school principals and teachers in the school, so both the teachers and the school principals have a great role in creating the trust.

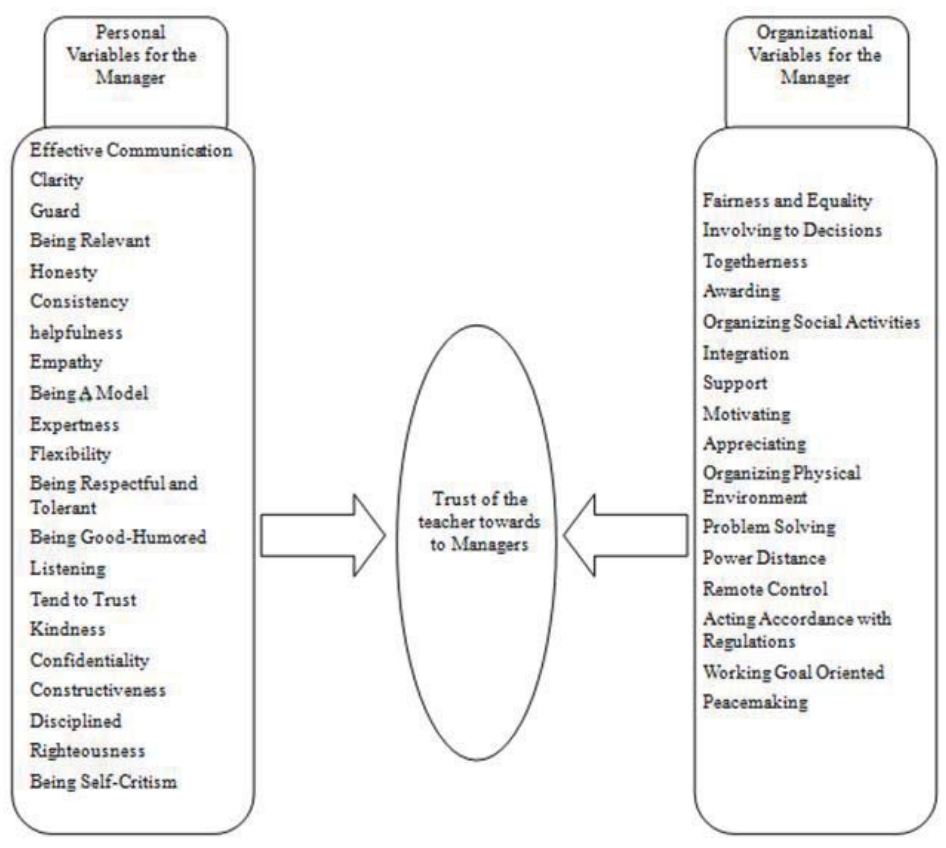

Figure 1. The Trust Basis for the Managers According to the Teachers 
As stated in the hypothetical part, trust affects most pf the variable in a positive or negative way. For this reason, teachers need to increase the level of confidence towards the school principals. As shown in the model we have developed, school principals need to be managed by controlling the variables that affect confidence in order to increase confidence in principals. . In this context, we can make the following recommendations for confidence-building for the principals. School principals;

- Act the teachers equal and fair,

- Involve the teachers into the decisions taken at school,

- Have the ability of efficient communication,

- Should be clear to the teachers,

- Guard the teachers from other elements and ensure the safety,

- Show interest in teachers,

- Should make the teachers together,

- Should behave honestly towards the teachers,

- Should be consistent in their behaviors,

- Should have a benevolent behavior,

- Should award the success,

- Should emphasize with the teachers while communicating,

- Should be a good example for the teacher and a model,

- Should organize social activities out-of-hours,

- Should continually improve his/her professional expertise,

- Should integrate with the teachers,

- Should support the teachers when it is needed,

- Should be flexible for the advantage of teachers while applying the rules,

- Should motivate the teachers constantly,

- Should make the teachers feel be respected,

- Should organize a physical environment for the teacher to make them work comfortably,

- Should be respectful and tolerant to the teachers,

- Should have the ability of problem solving,

- Should be good-humored to the teachers,

- Should collapse the power distance against the teachers,

- Should listen to the teachers,

- Should tend to trust for the teachers,

- Should comply with the rules of courtesy,

- Should be able to keep secrets,

- Should be constructive in any situations,

- Should act in accordance with the regulation,

- Shouldn't give the impression of a continuous control to the teachers and make remote control

- Should work goal-oriented,

- Should be disciplined,

- Should be peacemaker if there's a problem between the people,

- Should be true in expressions and behaviors,

- Should be self-critical.

As with any study, there are some limitations to this study. For this reason, we can make the following recommendations for the researchers. The results of this research with quantitative research, qualitative research approach can be tested. Some of the variables are determined as a basis for confidence in teachers' age, gender, seniority, and were judged to have more emphasis depending on the branch. In this context, other researchers can investigate the effect of the control variables of these variables. Research was just made on teachers working in primary schools in the district Izmit Kocaeli Province. A similar study can also be made by expanding the study area, adding the different school levels to the work area. 


\section{References}

Asunakutlu, T. (2002), Organizational Factors Related to the Development of Trust and an Evaluation, Muğla University Journal of the Institute of Social Sciences, Fall 2002, Issue 9.

Boru, D. (2001), The first step in the creation of a climate of trust in organizations, 9. Proceedings of the National Management and Organization Congress, 23-26 May 2001, Istanbul.

Cubukcu, K. (2010), In terms of the concept of organizational trust, organizational commitment and its effects on teachers (Tourism Vocational High Schools One Application), Published Master's Thesis, Gazi University, Institute of Educational Sciences, Ankara, Turkey.

Demircan, N. and Ceylan, A. (2003), The Concept of Organizational Trust: Causes and Consequences, Dincer, Ö. (1996). Business Management. Istanbul: Beta Publishing and Distribution Co., Ltd.

Egerci, T.C. (2009). Primary school teachers are exposed to mobbing effect of the level of organizational trust, Published Master's Thesis, Sakarya University, Institute of Social Sciences, Sakarya.

Eren, E. (1998), Management and Organization. Istanbul: Beta Publishing

Eser, G. (2007), The ethical climate and organizational commitment, the effect of trust in the manager, Published Master's Thesis, Marmara University, Institute of Social Sciences, Istanbul, Turkey.

Gumus, M. (1999), Golden Rules for Success in Management, Istanbul: Alfa Publications.

Mahiroglu, A and Buluc, B. (2003). Physical punishment in secondary education institutions, Gazi University, Technical Education Faculty, Ankara, Turkey.

Mayer, R. C., Davis, J. H., and Schoorman, F. D. (1995). "An Integrative Model of Organizational Trust." The Academy Of Management Review, 20: 709-734.

Miles, B. M. and Huberman A. M., (1994). Qualitative data analysis: An expanded source book. 2nd ed. California, USA: Sage Publications, p:27

Oren, K. (2007), Social Equity "Trust" Performance Impact Factor and Labor, Erciyes University Journal of Public-Business, S.1, p.7190.

Orucu, E. (2006). Celal Bayar University of Management and Economics Journal Year: 2006 Vol: 13 Issue: 1

Ozmen F. and Gungor A. (2008), Educational Inspection Ethics, Inonu University, Faculty of Education, Vol: 9, Q.15, p :137-155.

Pala, A. (2008). A Study on Teacher Candidates' Levels of empathy, Pamukkale University Journal of the Faculty of Education Year 2008 (1) 23 Issue 13

Paker, N. (2009), The relationship between organizational commitment and organizational trust in the primary school teachers (Sakarya province instance), Published Master's Thesis, Sakarya University, Institute of Social Sciences, Sakarya.

Polat, S. (2007), Secondary school teachers' perceptions of organizational justice, and organizational citizenship behaviors, the relationship between levels of organizational trust, Published PhD Thesis, Kocaeli University, School of Social Sciences, Ankara.

Polat, Ozgur. (2009), "Turkey's Foreign Trade Data in Forecasting A Comparative Analysis of Artificial Neural Networks and Box-Jenkins Models", Atatürk University, Institute of Social Sciences, Unpublished PhD Thesis.

Robbins, S.P. \& Decenzo, D.A. (2000). Fundamentals of Management of E-Business. Prentice Hall College Div; 3rd Sg edition

Sisman, M. (2001), Introduction to Teaching Profession, Pegem A Publications, Ankara, Turkey.

Tan, H. H. and Tan, C. S. (2000). Toward the differentiation of trust in supervisor and trust in organization. Genetic, Social, and Psychology Monographs, 126(2), 241-260.

TDK, Contemporary Turkish Dictionary, Internet Source: http://www.tdk.gov.tr/index.php?option=com_gts\&view=gts access: 03:05:12

Terzi, A. R. (2000), University Students' perceptions of research on power distance, uncertainty avoidance, Journal of Social Sciences, Balikesir University, Faculty of Education

Uzbilek, A. (2006), The Effects of Organizational Trust in Social Relations Sub-dimensions of organizations: The Case of Capital University, published Master's Thesis, Baskent University, School of Social Sciences, Ankara.

Unsal, P. (2004). Perceptions of Organizational Trust. Proceedings of Symposium on Modern Trends in personal development, Ankara Training and Doctrine Command, ss.225-237.

From Wikipedia, the free encyclopedia, Internet Source: http://tr.wikipedia.org Accessed: 03:05:12

Yildirim, A. and Simsek, H. (2005), Qualitative Research Methods in Social Sciences, Ankara: Seckin Publications.

Yilmaz, E. (2006), The level of organizational trust school administrators in schools and some of the variables examined for ethical leadership, Published PhD Thesis, Selcuk University, Institute of Social Sciences, Konya.

Yilmaz, K. (2004), Supportive Leadership Behaviours of School Principals in schools and Primary School Teachers' Opinions about the relationship between trust, Inonu University Journal of the Faculty of Education, P. 8, Volume: 5, Internet Source: http://web.inonu.edu.tr/ efdergi / journal / KursadY.htm Accessed: 13/04/2012. 
